Background: Today, after lung cancer, breast cancer is the second main cause of death in women worldwide. Amongst Pakistani women of all literary groups as well as in women of all age groups, the most common cancer is breast cancer. Objective: The primary objective of this study was to assess the complete in formation about breast cancer, its signs, indications, an orderly process and understanding about the management of this disease in female students in a Pakistani university.

Material and methods: This questionnaire-based survey study was carried out during February-April, 2011 at COMSATS Institute of Information Technology (CIIT), Abbottabad, Pakistan. Five hundred of university students of twelve different departments were asked to fill out a questionnaire by students of pharmacy along with an experienced pharmacist faculty member. Participants were asked 27 questions on the awareness of breast cancer and six questions were asked which were related to their attention about breast cancer and its management.

Results: Mean age of the participant students was 21.5 years. It was evident from the results that a large number of students did not have sufficient knowledge, or had no awareness of breast cancer. Regardless of extensive international and national public education programmes, more than $66 \%$ of the female students at CIIT were aware of breast cancer, and its examination and screening practices such as breast self-examination and clinical breast recommendations. The students also reported that their family physicians had never motivated them to have clinical breast examinations. Conclusion: This study emphasized the urgent need to arrange a breast cancer awareness crusade in CIIT, and other institutes as well, highlighting the symptoms, diagnosis and management of breast cancer. Since Pakistani females do not generally connect to the screening practices, nurses and female health visitors should jointly instruct women on the potential for early finding of cancer using a suitable screening tool such as the breast self-examination.

Key words: survey, symptoms, screening, pharmacy practice.

\section{Assessment of breast cancer literacy among female students in a Pakistani university}

\author{
Ghulam Murtaza, Sadaf Imtiaz Abbasi, Hina Irum, Mehreen Khan Jadoon, \\ Izhar Hussain
}

Department of Pharmaceutical Sciences, COMSATS Institute of Information Technology, Abbottabad, Pakistan

\section{Introduction}

Every year, a breast cancer campaign, named Pink Ribbon, is carried out in Pakistan to make females aware of breast cancer, its examination and screening practices such as Breast Self Examination and Clinical Breast Recommendations [1]. It is a matter of sadness that out of all Asian nations, the highest occurrence of breast cancer is observed in Pakistani females [2], and thus the percentage of women's death due to breast cancer is very high in Pakistan [3]. Out of all types of cancer in females, $38.9 \%$ of Pakistani females suffer from breast cancer [4]. In addition, 90,000 new breast cancers are adding to this figure [5]. The majority (43.7\%) of the females come to know about their suffering from cancer when the cancer has badly spread in their body, which results in their silent death [1].

In 2004, the Pink Ribbon Organization with the cooperation of the Institute of Nuclear Medicines and Oncology, Pakistan Atomic Energy Commission, arranged a breast awareness and diagnostic mobile campaign in a big city of Lahore, Pakistan including its surrounding areas, and also implanted a modern mammogram machine. Free diagnosis and consultancy was provided to females [6]. However, the Pink Ribbon Organization has reported that very few females benefited from this facility, and no serious interest of females was observed towards the screening of this deadly disease [4]

About 50 to $60 \%$ of Pakistani women at stage 3 and 4 of breast cancer gain very little or no benefit from any kind of therapy and many Pakistani women are exaggerated by breast cancer annually [7-9]. In developing countries, the main causes of late management of breast cancer are social and cultural factors, such as discrimination, religiosity and belief in herbal remedies [10].

In Pakistan, there is no massive source of information regarding breast cancer. The aim of this study was to assess university students' awareness about breast cancer and also to highlight the importance of knowledge and treatment of this disease among the female students of CIIT.

\section{Material and methods}

Study design and location

A cross-sectional survey was carried out from 25 February to 28 April 2011 at COMSATS Institute of Information Technology (CIIT), Abbottabad, Pakistan. From twelve different departments of CIIT, 500 female students (mean age $21.5 \pm 2.3$ years) having the ability to understand the questionnaire and with no personal history of breast cancer were chosen for this survey-based study. The target population consisted of female students of different departments of CIIT, Abbottabad. The least education prerequisite for inclusion in this study was twelve years of education in science. The research was conducted among undergraduate and graduate students. A two-stage random sampling 
methodology was employed. During stage 1, students were selected through simple random sampling and stage 2 covered the assortment of students from other locations. The students were briefed on the aim of the study and then consent to participate in the study was obtained from the students. The completion of questionnaires was conducted in the presence of an expert researcher for assisting the respondents, if required. This study was approved by Departmental Board of Studies, CIIT.

\section{Data collection}

The sampling method used was stratified random sampling. Twelve different department of university were regarded as strata. List of registered female students was acquired from each department and a computer generated easy arbitrary sample of female students was picked. After taking an informed consent, the recognized female students were interviewed through a validated questionnaire by a trained interviewer (researcher). The questionnaire consisted of questions which helped to provide information related to socio-demographic individuality and awareness of breast cancer. The questionnaire was prepared on the basis of knowledge extracted from journals $[1,9,10]$. The questionnaire, written in English, was pre-tested on a pilot scale using a sample of 30 female students taken from the target population. The final questionnaire consisted of 33 questions. Approximately, each respondent consumed fifteen minutes to complete the interview. Different timings were set for the survey so that the selected students could be approached. On average, two attempts were made to find a student. With the aim of evading contagion among students within a department, the survey for every department was completed in the shortest feasible duration. The pamphlets having information regarding breast cancer and breast self-examination were distributed to the students at the end of survey in each department.

\section{Data analysis}

Using SPSS version 13.0, the collected data were analysed with a significance level set at $P<0.05$.

\section{Results}

Participants taking part in this study had a mean age of $21.5 \pm 2.3$ years. The percentage of undergraduate and postgraduate students was $65 \%$ and $34 \%$, respectively. Results are summarized in Table 1. Responses to important questions regarding general knowledge about breast cancer are as follows: $44 \%$ of female students correctly believed that breast cancer was the foremost cause of women's death; however, $56 \%$ of female students did not believe that breast cancer could be mainly responsible for mortality in women. Many (77\%) of the students were aware that breast cancer is controlled growth of breast cells. The majority (86\%) of the students were also aware of higher occurrence of breast cancer in women than men. Greater percentage (42\%) of Pakistani women is affected from breast cancer in Asia and every year few women die of breast cancer was correctly answered by $53 \%$ and $44 \%$ of students, respectively. Breast can- cer refers to benign tumour, and an earlier diagnosis provides a better chance to beat it - these were correctly answered by $36 \%$ and $78 \%$ of students, respectively.

Responses to important questions regarding knowledge of breast cancer risk factors and symptoms were as follows: The students who responded correctly that cigarette smoking, old age, obesity and family history are important risk factors for breast cancer development were 40\%, 46\%, 41\% and $41 \%$, respectively. Also, $53 \%$ of the students were correct in the view that exercise reduces the chances of breast cancer. Frequent $X$-ray exposure can lead to breast cancer was also correctly answered by $48 \%$ of students. The feeling of pain in the breast region and bump under the armpit were the most normally appropriately recognized symptoms of breast cancer by $49 \%$ of the students. First child after exceeding 30 years of age (33\%) and premature onset of menses (55\%) related to breast cancer were also correctly recognized.

Responses to important questions regarding knowledge of breast cancer treatment were as follows: About $49 \%$ and $63 \%$ of students were aware of clinical breast examination (CBE) unexpectedly $49 \%$ and breast self-examination (BSE), respectively. Women after breast cancer treatment can enjoy a happy life was suggested by $58 \%$ of students. $62 \%$ of respondents believed that treatment of breast cancer is simple. Treatment of breast cancer is a long-term and painful process was believed by $89 \%$ of students. $54 \%$ of the students wrongly considered that mammograms, ultrasound, MRI, CAT scans and PET scans are the tests for screening and diagnoses. Surgery is useful in breast cancer was correctly considered by $43 \%$ of the students. Size, stage, lymph node status, and hormone receptor status can affect the treatment plan for breast cancer was wrongly proposed by $50 \%$ of the students. The students (68\%) also reported that mammograms are not as effective at detecting any change in premenopausal women because their breast tissue is denser. All above mentioned student's responses (results) were significantly $(p<0.05)$ different from their corresponding options i.e. difference between correct and wrong answers were significant $(p<0.05)$

\section{Discussion}

Less common knowledge of symptoms and risk factors may be the cause of late detection of breast cancer in developing countries such as Pakistan and previous reports are also confirmed by our conclusion [8, 11-18]. Despite symptoms of disease, it is seen that older adults are not expected to seek any type of help as these symptoms may not affect their functioning or cause them any pain [9, 10, 18-20]. The older age group has insufficient knowledge of symptoms and risk factors of breast cancer and thus they are at increased risk of developing breast cancer. In treatment of breast cancer, surgery may be helpful; this is agreed by $43 \%$ of participants. Lymph node status, size, hormone receptors and stage affect the treatment of breast cancer; this is proposed by $50 \%$ of participants. Students of different departments and different economic groups took part in this study and study variations re due to different study groups. Mammography and CBE have the ability to reduce mortality due to early detection and treatment; there is reliable evidence 
Table 1. Responses of students to various questions

\begin{tabular}{|c|c|c|}
\hline Questions & $\begin{array}{l}\text { Correct } \\
\text { percentage }\end{array}$ & $\begin{array}{l}\text { Wrong } \\
\text { percentage }\end{array}$ \\
\hline Breast cancer was the foremost cause of women death & 44 & 56 \\
\hline Breast cancer is controlled growth of breast cells & 77 & 23 \\
\hline High occurrence of breast cancer in women than men & 86 & 14 \\
\hline Greater percentage of Pakistani women is affected from breast cancer in Asia & 53 & 47 \\
\hline Every year few women die of breast cancer & 44 & 56 \\
\hline Breast cancer refers to benign tumor & 36 & 64 \\
\hline An earlier diagnosis provides a better chance to beat breast cancer & 78 & 22 \\
\hline Cigarette smoking is important risky factor for breast cancer development & 40 & 60 \\
\hline Old age is an important risky factor for breast cancer development & 46 & 54 \\
\hline Obesity is an important risky factor for breast cancer development & 41 & 59 \\
\hline Family history is an important risky factor for breast cancer development & 41 & 59 \\
\hline Exercise reduces the chances of breast cancer & 53 & 47 \\
\hline Frequent $\mathrm{X}$-ray exposure can lead to breast cancer & 48 & 52 \\
\hline $\begin{array}{l}\text { The feeling of pain in the breast region and bump under armpit were the most normally appropriately } \\
\text { recognized symptoms of breast cancer }\end{array}$ & 49 & 51 \\
\hline First child after 30 years of age is related with breast cancer & 33 & 67 \\
\hline Premature onset of menses is related with breast cancer & 55 & 45 \\
\hline Awareness of Clinical Breast Examination (CBE) & 49 & 51 \\
\hline Awareness of Breast Self Examination (BSE) & 63 & 37 \\
\hline Women after breast cancer treatment can enjoy happy life & 58 & 42 \\
\hline Treatment of breast cancer is simple & 62 & 38 \\
\hline Treatment of breast cancer is long term and painful process & 89 & 11 \\
\hline Mammograms, ultrasound, MRI, CAT-scans and PET scans are the tests for screening and diagnoses & 54 & 46 \\
\hline Surgery is useful in breast cancer & 43 & 57 \\
\hline Size, stage, lymph node status, hormone receptor status can affect treatment plan for breast cancer & 50 & 50 \\
\hline $\begin{array}{l}\text { Mammograms are not as effective at detecting any change in pre-menopausal women because their } \\
\text { breast tissue is denser }\end{array}$ & 68 & 32 \\
\hline
\end{tabular}

for this in the literature $[18,20]$. It is controversial concept since clinical trial, the role of CBE in mortality reducing $[13$, $17,19]$ and practicing is beneficial in reducing mortality. The women who are taught BSE show consequent use of health resources, increased apprehension level and more benign biopsies at a higher rate of physician visit $[12,15]$. There is absence of a breast screening programme and nationwide population mammography by BSE in developing countries because of limited resources. BSE is not only suitable up to standard and right but also considered to be an easy, low cost, non-persistent and harmless intervention [1]. A common identified risk factor was the family history. It is necessary to recognize complex risk factors of breast cancer such as late menopause and screening practices for early breast cancer detection. Medical facilities should also be provided to help in seeking benign symptoms and to improve symptomatic knowledge [12].
On breast cancer management and about it outcomes, an enormous number of our study subjects had the right concepts. Treatment of breast cancer is a painful and long-term process; the majority (89\%) of the students had a negative perception of it. This survey showed the need for improving breast cancer knowledge and educational programmes by the clinical setting and mass media. Potential carcinogens such as cigarette smoking and frequent $X$-ray exposure should be advertised and a diet containing less saturated fat and rich in fibre should also be promoted. Breast cancer information should be disseminated by radio broadcasts and television and by distributing leaflets. Television and radio are the best way to get to a vast audience but the advantages are achievable for only the people for whom these are accessible. People like to learn about breast cancer issues from their healthcare providers; thus they should provide proper counselling to the public for improving breast cancer knowledge. 


\section{Limitations of study}

Further studies are required for the identification of the female students' knowledge about breast cancer. This survey was conducted only at one institution which was a limitation of this study. The inclusion of other institutions in such study may produce different results as a result of an extensive survey. Another limitation is that this survey instrument was not validated.

In conclusion, students had vast knowledge about clinical breast examination and breast self-examination, dealing with breast cancer and on the outcomes of treatment, but as far as indications and manifestation of breast cancer is concerned, not many of the Pakistani university students had adequate knowledge, which was incomplete as well, and many of them had partial knowledge of the usual account of breast cancer. This study emphasized the urgent need of improving a breast cancer awareness crusade in CIIT, and other institutes as well, highlighting the symptoms, diagnosis and management of breast cancer. Since Pakistani females do not generally connect to the screening practices, nurses and female health visitors should jointly instruct women on the potential of early finding of cancer using a suitable screening tool such as breast self-examination.

\section{References}

1. Usmani K, Khanum A, Afzal H, Ahmad N. Breast carcinoma in Pakistani women. J Environ Pathol Toxicol Oncol 1996; 15: 251-253.

2. Vastag B. Developing countries face growing cancer burden. J Nat Cancer Inst 2006; 98: 1106-1107.

3. Baig S, Ali TS. Evaluation of efficacy of self breast examination for breast cancer prevention: a cost effective screening tool. Asian Pac J Cancer Prev 2006, 7: 154-156.

4. Bhurgri Y. Karachi Cancer Registry Data-implications for the National Cancer Control Program of Pakistan. Asian Pac J Cancer Prev 2004; 5: 77-82.

5. Bhurgri H, Gowani SA, Itrat A, Samani S, Zuberi A, Siddique MS, Qidwai W, Bhurgri Y. Awareness of cancer risk factors among patients and attendants presenting to a Tertiary Care Hospital in Karachi, Pakistan. Br J Cancer 2008; 58: 584-588.

6. Hussain MM, Ansari AK. Late presentation of carcinoma breast in Pakistani women. Pak Armed Forces Med J 1996; 46: 11-15.

7. Malik IA. Clinico-pathological features of breast cancer in Pakistan. J Pak Med Assoc. 2002; 52: 100-104.

8. Siddiqui T, Sabih M, Salam A, Khan S. A survival analysis of metastatic breast cancer in Pakistani patients. J Pak Med Assoc 2001; 51: 120-122.

9. Ahmed F, Mahmud S, Hatcher J, Khan SM. Breast cancer risk factor knowledge among nurses in teaching hospitals of Karachi, Pakistan: a cross-sectional study. BMC Nursing 2006; 5: 1-7.

10. Hadi MA, Hassali MA, Shafie AA, Awaisu A. Evaluation of breast cancer awareness among female university students in Malaysia. Pharm Pract 2010; 8: 29-34.

11. Hisham AN, Yip CH. Spectrum of breast cancer in Malaysian women. World J Surg. 2003; 27: 921-923.

12. Rossi S, Cinini C, Di Pietro C, Lombardi CP, Crucitti A, Bellantone R, Crucitti F. Diagnostic delay in breast cancer: correlation with disease stage and prognosis. Tumori 1990; 76: 559-562.

13. Hisham AN, Yip CH. Overview of breast cancer in Malaysian women: A problem with late diagnosis. Asian J Surg 2004; 27: 130-133.

14. Rashidi A, Rajaram SS. Middle Eastern Asian Islamic women and breast self-examination. Needs assessment. Cancer Nurs 2000; 23: 64-70.

15. Rajaram SS, Rashidi A. Asian-Islamic women and breast cancer screening: a socio-cultural analysis. Women Health 1999; 28: 45-48.

16. Odusanya OO, Tayo OO. Breast cancer knowledge, attitudes and practice among nurses in Lagos, Nigeria. Acta Oncol 2001; 40: 844-848.
17. Grunfeld EA, Ramirez AJ, Hunter MS, Richards MA. Women's knowledge and beliefs regarding breast cancer. Br J Cancer 2002; 86: 1373 1378.

18. Harirchi I, Ebrahimi M, Zamani N, Jarvandi S, Montazeri A. Breast cancer in Iran: a review of 903 case records. Public Health 2000; 114: 143-145.

19. Okobia MN, Bunker CH, Okonofua FE, Osime U. Knowledge, attitude and practice of Nigerian women towards breast cancer: A cross-sectional study. World J Surg Oncol 2006, 4: 1477.

20. Paul C, Barratt A, Redman S, Cockburn J, Lowe J. Knowledge and perceptions about breast cancer incidence, fatality and risk among Australian women. Aust NZ J Public Health 1999; 23: 396-400.

\section{Address for correspondence}

\section{Ghulam Murtaza}

Department of Pharmaceutical Sciences

COMSATS Institute of Information Technology

Abbottabad, Pakistan

tel: +923142082826

fax: +92992383441

e-mail: gmdogar356@gmail.com 